\title{
CONFISSÕES DE RALFO: O AVESSO DAS MEMÓRIAS
}

\author{
NOEMI H. B. DE PERDIGÃO - CEFET/PR
}

\section{Resumo:}

\begin{abstract}
A literatura brasileira dos anos 70 foi marcada pelos romancereportagem e por textos memorialistas. Confissões de Ralfo: uma autobiografia imaginária rema contra a corrente. Num momento de denúncias sociais e narradores onipotentes desafina o coro e apresenta um jogo polifônico no qual um narrador se traveste de personagem para, assim narrar um destino imaginário, mais interessante do que o real.
\end{abstract}

Para seguirmos os passos desse narrador e desvendar suas armadi Ihas,optamos pela descrição que Mikhail Bakhtin faz das formas de enunciação do discurso do narrador e do discurso citado, de modo a entender como e porque ocorre essa coexistência discursiva na obra.

Desde sempre a literatura brasileira vem sendo marcada por uma necessidade do referencial, de expressar a realidade. Essa busca do real reflete a tentativa de elaboração de uma identidade nacional, procurada incessantemente desde o Romantismo, mas ainda inesgotada.

No momento da consciência amena do atraso, como o define Antônio Cândido(1), predominou uma literatura que aliava a noção de natureza à de pátria, acreditando que a grandeza de uma estava ligada à variedade e exotismo da outra. Como a terra, o homem brasileiro - o índio - é forte, poderoso, não se deixa abater por adversidades.

Após a Segunda Guerra Mundial, a postura dos intelectuais e escritores muda: a noção idílica de Brasil dá lugar à realidade do atraso sócio-econômico, à consciência do subdesenvolvimento. Os escritores passam a discutir os problemas do país e tentar, via uma ficção participante, acelerar a revolução, garantia de uma vida melhor para todos.

Na década de 70 essa postura é retomada. Mais do que fazer literatura ou pesquisar novas formas de expressão, ao escritor cabia dizer o interdito, informar, já que o canal informativo por definição, o jornal, não podia fazê-lo. Surge, então, uma literatura parajornalística, na qual homem brasileiro será o marginal, a pantera, e sociedade brasileira, a prisão e outros microcosmos equivalentes. Impossibilitados de dizerem a totalidade, os autores descrevem o específico, alegorizando: (...) a alegoria é a forma alusiva do fragmentário (2).

A o lado desta literatura-reportagem surgem, mais no final da década, os textos memorialistas, com o mesmo objetivo de registrar a história imediata ou imediatamente anterior. Em ambos, os "fatos históricos" obedecem a enfoques pessoais, ou pessoalmente escolhidos como indicadores da realidade maior, o que leva à pergunta, já proposta por Davi Arrigucci Júnior: A questão que eu estou levantando é se eles [ os livros ] estão, de fato fazendo esta história, se de fato eles estão tratando do conteúdo de verdade que eles estão vivendo. Se eles não estão mergulhados na pura singularidade (3).

Entretanto, esta literatura que se queria participante e revolucionária, já que denunciava as opressões sociais e revelava a "verdadeira" identidade nacional, não era censurada. Por quê? Ao construir uma "identidade nacional" inquestionável, esses autores colaboram com o Estado, no sentido de representar um país sem divisões: E até o negativo da foto interessa à Política Nacional de Cultura. Em positivo ou negativo, o texto-retrato tende a ocultar fraturas e divisões, a construir identidades e reformar nacionalismos pouco críticos (4). Neste momento - por volta de 1975 -, ao Estado interessava mais fazer com que se produzisse num determinado sentido do que simplesmente suprimir. 
Simultaneamente a essa produção calcada na realidade, surgem outros possíveis caminhos na literatura, percorridos por aqueles interessados em desmistificar esse retrato retocado de Brasil, mostrando os dois lados da moeda e, principalmente, procurando novas formas de expressar esse momento. Textos que não escondem seu caráter ficcional e nos quais não há uma verdade apresentada por um narrador todopoderoso, mas sim múltiplas verdades, ditas por diferentes vozes: do louco à personagem definida como tal.

Mais do que naqueles romances-reportagem,será nestes romances-ruptura que se refletirá o momento histórico, no sentido de influenciador da criação, pois, segundo Mikhail Bakhtin, toda enunciação é marcada por componentes sociais e ideológicos, expressos nas formas de apresentação do discurso (5).

Confissões de Ralfo de Sérgio Sant'Anna, o romance em questão neste artigo, inscreve-se mais na linha da ruptura do que na do paradigma. No momento do auge das memórias, constitui seu avesso, não existindo uma única voz apresentando fatos verossímeis, mas um jogo polifônico, no qual um narrador, insatisfeito com o seu presente e descrente do seu futuro, se traveste de personagem para, assim, narrar um destino imaginário, mais interessante do que o real.

A leitura proposta se aterá às formas de apresentação dos fatos, às inter-relações discursivas que configurem essa troca de vozes. Tentar-se-á relacionar essa postura discursiva a uma postura ideológica mais ampla, de desmistificação do discurso do poder, à medida em que a aceitação de um narrador onipotente e direcionador da leitura na obra literária implica o aval ao discurso repressivo, ditatorial veiculador de verdades absolutas - dos detentores do poder.

Para se falar do narrador em Confissões de Ralfo, é necessário pensar na significação da existência de duas vozes principais na narrativa: a do narrador e a de Ralfo. Como referência teórica para a análise da questão da narração e do narrador, optou-se pela descrição de Bakhtin (6) . Com base na sua discussão das formas de enunciação do discurso do narrador e do discurso citado, pretendemos examinar como se dá a coexistência discursiva na obra e o porquê dessa troca de vozes. Bakhtin define discurso citado (...) como a enunciação de uma outra pessoa, completamente independente na origem, dotada de uma construção completa e situada fora do contexto narrativo que (...) passa para o contexto narrativo conservando o seu conteúdo e ao menos rudimentos de sua integridade lingüística e da sua autonomia estrutural primitivas (7).

Em Confissões de Ralfo, a posição de discurso citado é intercambiante: umas vezes é o da personagem, outras, o do narrador, tratados no mesmo plano enunciativo.

Antes mesmo da folha de rosto, existe na obra um prólogo, na $1^{\text {a }}$ pessoa do singular, em que o narrador explica o objetivo de sua opção de se transformar em personagem: escrever um romance. Sendo sua vida pouco interessante, ele resolve encarnar uma personagem para, então, narrar o que quiser, sem medo do ridículo ou da crítica. Ralfo é seu porta-voz, pela boca de quem poderão ser expressos fatos inverossímeis, fantasiosos, porém mais interessantes do que os reais. Esse discurso pretende configurar o contexto narrativo e, ao mesmo tempo, introduzir o de Ralfo. Contudo, o narrador não deixa de marcar sua presença, avisando ao leitor que Ralfo é ele e que seu discurso perpassará toda a narrativa, mesmo que em alguns momentos apareça sob uma capa de objetividade, na $3^{a}$ pessoa do singular ou na boca de terceiros.

Além do prólogo, ainda há um roteiro de leitura e três epígrafes, uma das quais do próprio Ralfo, apresentado como um verdadeiro autor, um pouco megalomaníaco talvez, à medida em que deseja escrever um super-romance com um superenredo girando em torno da vida de uma superpersonagem: ele mesmo.

A obra, além da divisão em capítulos, também se compõe de livros que podem ser lidos separadamente, como sugere o narrador no roteiro. Esta estruturação, que dá autonomia a cada livro, permite a apresentação de diferentes situações sem que seja necessária uma continuidade espaço-temporal explícita, que, porém, existe internamente a cada livro, na apresentação de situações verossímeis ou não.

O livro I se inicia com a enunciação do narrador, que está se convertendo em Ralfo, uma personagem: O primeiro passo é abandonar a cidade e qualquer vínculo com a existência anterior (...) compenetrar-me de que sou Ralfo, concebido do nada (8). A partir disso, o discurso de Ralfo - o discurso citado - passa a funcionar como contexto narrativo, embora em alguns momentos sua posição de discurso de outrem seja 
revelada: Divagações espontâneas e sem importância de Ralfo, enquanto ele não se manda definitivamente (9).

O discurso de Ralfo, portanto, é introduzido pelo do narrador, apesar de no decorrer da narrativa tornar-se o dominante. A enunciação do narrador é que passa a ser vista como subjetiva, como discurso de outrem. Segundo Bakhtin, na literatura essa dominância do discurso citado sobre o contexto narrativo ocorre quando aparece um narrador que substitui o autor propriamente dito. Em Confisões de Ralfo o discurso do narrador é substituído pelo da personagem, ficando ambos no mesmo plano, o que possiblita a troca discursiva no decorrer da narrativa. A explicitação desse jogo de vozes se fará na nota final, quando o narrador - agora assinando Sérgio Sant'Anna - fala do destino do livro e de Ralfo, após ter se "desvencilhado" dele no epílogo, assumindo o discurso e revelando sua "presença" não-declarada em toda a narrativa.

No referente à inter-relação discursiva, a enunciação de Ralfo é apresentada como discurso direto, emergindo do discurso do narrador, sem nenhuma marca de enunciação que indique essa passagem. Não existem fronteiras entre o discurso do narrador e o da personagem, constituindo um fenômeno lingüístico: as interferências de discurso (10). Isso permite a relativização da onipotência do discurso do narrador geralmente o discurso do poder nas obras literárias, já que interfere não só no desenrolar dos acontecimentos, como também na sua apresentação ao leitor, 'a medida em que à enunciação de Ralfo é atribuída a mesma importância que à do narrador.

E m Confissões de Ralfo essa polifonia discursiva possibilitará a narração de quaisquer situações, verossímeis ou não, harmônicas entre si ou não. Não impedirá, também, alusões à realidade imediata.

Ralfo se quer um ator e no decorrer da narrativa desempenha vários papéis, de revolucionário, cidadão comum, a show-man e escritor. Sempre em busca de fatos memoráveis, vai tentando (...) construir um mundo ficcional, a que a realidade possa posteriormente adaptar-se (11).

A mudança na marca enunciativa dos discursos também é muito explorada na obra: Ralfo usa a $1^{\underline{a}}$ pessoa do singular quando quer ser sujeito absoluto do narrado; nos momentos em que o narrador se cola à personagem, aparece a $1^{\text {a }}$ pessoa do plural, bem como naqueles em que Ralfo quer trazer mais alguém para seu discurso. O discurso impessoal registra os momentos pós-atentado de Ralfo, quando ele não se sabe morto ou vivo:

\author{
Como um esguio Raskolnikov, vou racionalizando meus \\ crimes, apalpando bolsas, vestidos, casacos, caixas de \\ papelão.(12)
}

$O$ ator se deixando levar pela representação, transformandose no personagem. Como Ralfo. Somos irmãos gêmeos. Por isso nos demos bem. Dois sinceros farsantes.(13)

\author{
Os pensamentos de um morto, talvez, que se esperava ser. \\ Mas se está vivo e o coração dispara com medo desse \\ desconhecido. (14)
}

Apesar de apresentado como um livro que trata da vida real de um homem imaginário ou da vida imaginária de um homem real (15), a preocupação com a verossimilhança externa não deixa de existir na obra. Em diferentes momentos, a alusão ao real se dá, geralmente com um toque irônico, como no caso do interrogatório - apesar de a introdução remeter à ocorrência de situações semelhantes na realidade. $O$ interrogatório, embora num contexto opressivo verossímil, é absurdo. Os interrogadores, ao invés de nomes e endereços, querem saber:

\author{
- Quem descobriu o Brasil? \\ - Pedro Álvares Cabral (...) \\ - E o que aconteceu antes, em 1492? \\ - A descoberta da América por Cristóvão Colombo.(16)
}

O non-sense deste interrogatório não só desmistifica, pela ironia, a apresentação de interrogatórios e 
torturas os mais "reais" possíveis nas obras daquele momento, como também explicita o absurdo que eram (são?) essas práticas. Apesar de responder exatamente ao que lhe é perguntado, Ralfo é agredido, por saber demais ou por suas respostas não agradarem os interrogadores:

\title{
- E o que é um maniqueísta? \\ - Alguém que segue uma doutrina fundada nos princípios opostos do bem e do mal (...) \\ Duas chibatadas por não ser um maniqueísta. (17)
}

\begin{abstract}
A gratuidade da violência é igualmente apresentada nesse avesso de interrogatório, comprovando mais uma vez que menos do que uma forma de se conseguir informações, esta é uma prática autoritária que serve como catarse para mentes psicopatas.
\end{abstract}

O interrogatório serve também para referências concretas, como uma crítica à arbitrariedade dos poderosos, e para reflexões de Ralfo sobre a obra:

- O que é arbitrariedade?

- Despotismo e capricho daqueles que se julgam com direito

a árbitro.

- Assim como nós?

- Assim como vós, senhores. (18)

- Mas o que é harmonia?

- Disposição bem ordenada entre as partes de um todo.

- E desarmonia?

- O contrário da harmonia.

- Assim como em vosso livro?

- Assim como em meu livro, senhores. (19)

Outros aspectos muito presentes na obra são a revelação de seu fazer poético e a discussão sobre literatura. O caráter ficcional da narrativa, já apresentado no prólogo, é realçado durante toda ela, atingindo o ápice no livro IX, sugestivamente denominado Literatura. Neste capítulo Ralfo terá suas memórias analisadas e avaliadas por uma banca de ilustres ministros - da Língua, dos Neologismos, dos Monólogos Exteriores, etc. - , que Ihe concederão, ou não, o título de Escritor. Como um espelho da Literatura e do próprio livro, aqui são discutidas questões como o objetivo de um escritor ao compor uma obra e o produto específico de uma criação literária - no caso o próprio romance. Ao falar de seu desejo de se tornar escritor, Ralfo não procura dar justificativas sociais ou literárias, mas realça o interesse do escritor em conseguir prestígio e dinheiro. Nesse momento, chama o leitor a desmistificar, com ele, as usuais explicações do porquê escrever, questionando o "papel social" do escritor:

\footnotetext{
- O que eu desejo, senhores, é um pouco de prestígio e dinheiro (...)

Era isso o que eu dizia, caros leitores, com toda a sinceridade do coração, pois poderia muito bem estar cacarejando que o meu objetivo era comunicar com o meu semelhante e auxiliar os povos do mundo a refletir sobre as agruras da condição humana ou, então, contribuir para maior glória das letras e das artes ou para combater 0 fascismo que assola o Planeta. (20)
}

Neste momento percebe-se claramente a interferência discursiva, já que essas opiniões, apesar de não expressas na 1a pessoa do plural, pertencem tanto a Ralfo como ao narrador e até, por que não, ao próprio 
autor. Confissões de Ralfo não objetiva adiantar a revolução social ou discutir filosoficamente alguma questão relevante. Não se está afirmando que foi composto com fins especificamente comerciais, mas sim que a narrativa não se inscreve na tradicção mitificadora do homem e/ou da literatura, nem se quer instrumento da revolução social, constituindo uma ruptura com essa maneira de se encarar a literatura. É Ralfo quem melhor ilustra essa postura:

\title{
O que eu queria era (...) contar estórias de cavaleiros, príncipes, mendigos e princesas. (...) Estórias que atiçassem a imaginação do povo e o fizessem compreender os demônios que devem expulsar para que o corpo e a alma se tornem transparentes. (21)
}

\begin{abstract}
Ele realça esse aspecto de "contador de histórias", sem contudo negar o caráter persuasivo de todo texto literário, que sempre deseja conquistar seu leitor e, de uma forma ou de outra, modificar a visão que ele tem do mundo e de si.
\end{abstract}

U m outro aspecto desmistificador é a intertextualidade, sempre irônica, presente na narrativa. Ralfo, personagem, convive com outras personagens de narrativas conhecidas - Alice, Lolita, Sancho Pança -, todas caricatas, atualizadas pelo olhar de Ralfo. Alice não é mais aquela menina curiosa; em sua nova roupagem, tem um pouco de Lolita, a ninfeta que influenciou uma geração. Pancho Sança é companheiro de pequenos furtos, nada possuindo do escudeiro racional de D. Quixote. Essa intertextualidade irônica acentua o caráter crítico da obra, já que até narrativas consagradas são vistas com olhos novos, desmistificadores.

A narrativa termina com seu próprio aniquilamento, com o romance sendo jogado para 0 alto e posteriormente recomposto de diferentes maneiras.

No epílogo o narrador se junta a Ralfo para, num jogo discursivo em que se alternam o discurso citado, entre aspas, e a enunciação do narrador identificado com a personagem, finalmente se desvencilhar dela. Nesse momento, o narrador assume um discurso na $3^{\text {a }}$ pessoa do singular, separando sua fala da de Ralfo para dar-Ihe um fim, após o que retomará o discurso na 1‥ pessoa do singular e a autoria do texto.

Todo esse artifício discursivo servirá para que o narrador explicite o processo de criação do livro: só após dar um fim à personagem, sente-se livre e capaz de retomar seu discurso. Na Nota Final isso fica patente quando o narrador - agora assinando com autor - sugere ao leitor que o desaparecimento de Ralfo era o fim mais indicado, pois ele já havia terminado sua obra. E, como ele, narrador, também chega ao fim da sua, sugere ao leitor a destruição do livro, visto que Ralfo já o fizera.

Esse desprendimento com relação à obra pode ilustrar uma postura incomum na época: o livro não é indispensavel e nem pretende revolucionar modos e costumes. É uma narrativa que, como todas, só viverá na relação com o leitor, criador virtual que dá existência real à obra. Confissões de Ralfo se define como literatura, e não como expressão de um real inquestionável. E como literatura, expressa as divisões de um real fragmentário, pela coexistência de diferentes falas e pela ironização de situações concretas, abrindo a possibilidade de leituras diversas de uma mesma realidade.

No auge dos textos memorialistas, Confissões de Ralfo constitui, ao lado de Em Liberdade, de Silviano Santiago, uma ruptura com a reconstrução de um período histórico via memórias pessoais. Aqui não interessa a representação de fatos concretos, mas a abertura à imaginação e à ironia. $O$ narrador autoritário, onisciente e extremamente pessoal - no sentido de marcar as personagens com seu discurso e tentar levar o leitor a uma única leitura do que está dito -, dá lugar a um narrador metamorfoseado em personagem , que cola seu discurso ao dela e até lhe dá predominância discursiva.

Percorrendo o caminho da ruptura face aos romances da época, a narrativa revela e discute seu caráter literário, ironiza situações caras às obras do período, como a do interrogatório e/ou tortura, atualiza personagens de outras obras, dá voz aos loucos, mostrando que os limites entre sanidade e loucura são tênues, narra peripécias e desejos. 
Num contexto histórico e literário autoritário - não esquecer que em 1975, se já não havia mais uma censura ativa, existiam os órgãos estatais de "apoio" à cultura ( Embrafilme, FUNARTE, INACEN e outros) que cooptaram muitos criadores -, em que predominava a visão maniqueísta de um narrador onipotente em oposição ao ditador onipotente, Confissões de Ralfo constitui uma tentativa de discutir, via desmascaramento da onipotência do narrador, o próprio arbítrio reinante no país. Nega-se a ser apenas o outro lado da moeda, como os romance-reportagem que apresentavam a sua visão de Brasil, tão ou mais fechada que a oficial. Nega-se também a encobrir seu caráter ficcional, a se apresentar como realidade.

Apesar de os aspectos ressaltados acima privilegiarem a invenção em lugar da representação, Confissões de Ralfo não é um texto destituído de referencialidade histórica. Mais do que nos retratos retocados de Brasil oferecidos pelos romance-reportagem, é em obras desse tipo que a verdadeira discussão sobre liberdade e opressão se dá, introduzida pela discussão do papel do narrador, do que é literatura hoje e pela pesquisa de novas formas de dizer o novo momento. Como afirmava Machado de Assis, a atualidade espaço-temporal de uma obra não está no falar de fatos da realidade imediata, mas sim na identificação do escritor com seu momento histórico: $O$ que se deve exigir do escritor, antes de tudo, é certo sentimento que o torne homem do seu tempo e do seu país, ainda quando trate de assuntos remotos no tempo e no espaço. (22)

NOTAS DE REFERÊNCIA

1 CÂNDIDO, Antônio. Literatura e Subdesenvolvimento. In: MORENO, César Fernandes, coord. América Latina em sua literatura. São Paulo: Perspectiva, 1979. p. 343.

2 ARRIGUCCI, Davi. Jornal, Realismo, Alegoria: o romance brasileiro recente. In: Achados e perdidos. São Paulo: Polis, 1979. p. 94.

3 ARRIGUCCI, Davi. p. 87.

4 SUSSEKIND, Flora. Literatura e vida literária: polêmicas, diários e retratos. Rio de Janeiro: Zahar, 1985. (Coleção Brasil: os anos de autoritarismo) p. 27.

5 BAKHTIN, Mikhail. Para uma história das formas de enunciação nas construções sintáticas. In: . Marxismo e filosofia da linguagem. São Paulo: Hucitec, 1986. p. 139-96.

6 BAKHTIN, Mikhail. p. 139-96.

7 BAKHTIN, Mikhail. p. 144-5.

8 SANT' ANNA, Sérgio. Confissões de Ralfo: uma autobiografia imaginária. Rio de Janeiro: Civilização Brasileira, 1975. p. 13.

9 SANT' ANNA, Sérgio. p. 14.

10 BAKHTIN, Mikhail. p. 169.

11 SANT' ANNA, Sérgio. p. 48.

12 SANT' ANNA, Sérgio. p. 25.

13 SANT' ANNA, Sérgio. p. 34.

14 SANT' ANNA, Sérgio. p.54.

15 SANT' ANNA, Sérgio. p. 2.

16 SANT' ANNA, Sérgio. p. 117.

17 SANT'ANNA, Sérgio. p. 119.

18 SANT'ANNA, Sérgio. p. 124.

19 SANT' ANNA, Sérgio. p. 126.

20 SANT' ANNA, Sérgio. p. 220-1.

21 SANT' ANNA, Sérgio. p. 228.

22 ASSIS, Joaquim Maria Machado de. Instinto de Nacionalidade. In: COUTINHO, Afrânio. Caminhos do pensamento crítico. Rio de Janeiro: Editora Americana, 1974. p. 345.

\section{REFERÊNCIAS BIBLIOGRÁFICAS}

1 ARRIGUCCI, Davi. Jornal, Realismo, Alegoria: o romance brasileiro recente. In: Achados e perdidos. São Paulo: Polis, 1979. p. 94.

2 ASSIS, Joaquim Maria Machado de. Instinto de Nacionalidade. In: COUTINHO, Afrânio. Caminhos do pensamento crítico. Rio de Janeiro: Editora Americana, 1974. p. 345.

3 BAKHTIN, Mikhail. Para uma história das formas de enunciação nas construções sintáticas. In: . Marxismo e filosofia da linguagem. São Paulo: Hucitec, 1986. p. 139-96. 
4 BENJAMIN, Walter. O Narrador: considerações sobre a obra de Nikolai Leskov. In: Magia e técnica, arte e política: ensaios sobre literatura e história da cultura. São Paulo: Brasiliense, 1985. p. 197-221.

5 CÂNDIDO, Antônio. Literatura e Subdesenvolvimento. In: MORENO, César Fernandes, coord. América Latina em sua literatura. São Paulo: Perspectiva, 1979. p. 343.

6 HOLLANDA, Heloísa Buarque de. \& GONÇALVES, Marcos Augusto. Política e literatura: a ficção da realidade brasileira. In: Anos 70, no 2. Rio de Janeiro: Europa, 1979. p. 7-81.

7 LEITE, Lígia Chiappini Moraes. O foco narrativo. São Paulo: Ática, 1985. (Série Princípios, 4) 8 SANT' ANNA, Sérgio. Confissões de Ralfo: uma autobiografia imaginária. Rio de Janeiro: Civilização Brasileira, 1975. p. 13.

9 SANTIAGO, Silviano. Vale quanto pesa: ensaio sobre questões político-culturais. Rio de janeiro: Paz e Terra, 1982.

10 SUSSEKIND, Flora. Tal Brasil, qual romance? Rio de Janeiro: Achiamé, 1984.

11 SUSSEKIND, Flora. Literatura e vida literária: polêmicas, diários e retratos. Rio de Janeiro:

Zahar, 1985. (Coleção Brasil: os anos de autoritarismo) p. 27.

12 TODOROV, Tzvetan. Estruturalismo e poética. São Paulo: Cultrix, 1976. 